\title{
MATHEMATICAL MODEL OF A PNEUMOHYDRAULIC BRAKE WITH A PRESSURE CONVERTER
}

\section{Sayel M. Fayyad, Waleed Momani, and Suleiman Abu-Ein}

Mechanical Engineering Department Al-Balqua Applied University.

Faculty of Engineering and Technology

Amman, Jordan, 11134, P.O. Box 15008

E-mail:waleed@yahoo.com

\section{(Received May 3, 2008 Accepted October 15, 2008)}

This study aims to building a mathematical model for pneumohydraulic brake system. Creating a pneumohydraulic brake system with a variable transfer attitudes or relation requires really a lot of complex works on modeling transient of such systems. After building the mathematical model it will be solved in order to investigate its final response and stability. It is found that the output pressure values $(P 1, P 2$, andP3) are increasing with time; displacements of pistons and may depend on pneumatic and hydraulic properties of the using medium.

KEY WORDS: pneumohydraulic brake system, variable transfer attitudes, factor of hydraulic resistance, viscosity factor, brake rigidity, preliminary deformation, and pliability.

\section{NOMENCLATURE}

\begin{tabular}{|c|c|c|c|}
\hline $\mathrm{A}_{\mathrm{B}}$ & $\begin{array}{l}\text { area of the piston according to a } \\
\text { pneumatic cavity }\left[\mathrm{m}^{2}\right]\end{array}$ & $\mathrm{P}_{3}^{\prime \prime}$ & $\begin{array}{l}\text { Pressure of the end of operation of } \\
\text { the relay }[\mathrm{Pa}]\end{array}$ \\
\hline$A_{i}$ & $\begin{array}{l}\text { area of working cavities of the } \\
\text { main and executive cylinders }\left[\mathrm{m}^{2}\right]\end{array}$ & $\mathrm{P}_{\mathrm{Bmax}}$ & maximal pressure of air $[\mathrm{Pa}]$ \\
\hline$c_{i}$ & $\begin{array}{l}\text { rigidity of the brake mechanism } \\
{[\mathrm{Pa}]}\end{array}$ & $\mathrm{P}_{4 \min }$ & $\begin{array}{l}\text { Pressure appropriate to the } \\
\text { beginning of cavitations [Pa] }\end{array}$ \\
\hline $\mathrm{F}(\mathrm{z})$ & $\begin{array}{l}\text { characteristic force of the brake } \\
\text { mechanism }[\mathrm{N}]\end{array}$ & $\mathrm{V}$ & $\mathrm{M} / \mathrm{S}$ dynamic viscosity N.S/ $\mathrm{m}^{2}$ \\
\hline $\mathrm{k}_{\varepsilon}$ & approximation factor; & $Y_{\mathrm{i}}$ & pliability \\
\hline $\mathrm{k}$ & parameter exhibitors & $\mathrm{y}_{\mathrm{i}}$ & units of a circuit; \\
\hline $\mathrm{L}_{\mathrm{i}}$ & pipes length [m] & $\mathrm{x}, \mathrm{y}, \mathrm{z}$ & coordinates of a rule \\
\hline $\mathrm{m}_{\mathrm{i}}$ & mass of a liquid $[\mathrm{Kg}]$ & $\beta$ & relative initial volume of air in a liquid; \\
\hline $\mathrm{P}_{\mathrm{B}}$ & $\begin{array}{l}\text { pressure of air in a pneumatic } \\
\text { cavity }[\mathrm{Pa}]\end{array}$ & $\rho$ & $\begin{array}{l}\text { density of the current liquid } \\
{\left[\mathrm{Kg} / \mathrm{m}^{3}\right]}\end{array}$ \\
\hline$P_{i}$ & $\begin{array}{l}\text { pressure of a liquid accordingly in } \\
\text { working cavities }[\mathrm{Pa}]\end{array}$ & $v$ & $\begin{array}{l}\text { kinematic viscosity factor of a } \\
\operatorname{liquid}\left[\mathrm{m}^{2} / \mathrm{s}\right]\end{array}$ \\
\hline \multirow[t]{2}{*}{$\mathrm{P}_{3}^{\prime}$} & $\begin{array}{l}\text { Pressure appropriate to the } \\
\text { beginning }[\mathrm{Pa}]\end{array}$ & $\begin{array}{l}\xi_{\mathrm{i}} \text { or } \\
(\mathrm{R})\end{array}$ & factor of hydraulic resistance \\
\hline & & $\Psi$ & spring constant $[\mathrm{N} / \mathrm{m}]$ \\
\hline
\end{tabular}




\section{INTRODUCTION}

Building a new brake system requires a full analysis in order to get a good efficiency and good performance. There were little studies using mathematical modeling -as a technique- concerned with such topic. These works were limited to some systems developed by some automobiles companies.

Guner et al. [1] presented some technique to check the validation of analytical model of vehicle brake system. In this work they presented a paper aimed to contribute to dynamic and thermal analysis of the braking phenomenon. Using this model, the equation of motion of a car has been phenomenon. Using this model, the equation of motion of a car has been derived for straight line braking. In this study the pressure variations in the brake hydraulic circuit versus pedal force had been determined. Afterwards, the expressions for friction torques and associated braking forces induced by hydraulic pressure had been taken into account, and substituted into the equation of motion of vehicle. In its last form, this equation had been numerically solved by means of the Newmark integration scheme; so, the distance traveled by car until stopping, along with its speed and deceleration, had been computed. Finally, a thermal analysis in the brake discs and drum had been carried out. An excellent agreement between numerical and test results had been observed. In addition, optimal pressure values for which the rear tires do not go to lockup had been obtained. Hedrick and Uchanski [2] provided solutions to two common brake control problems: variable brake torque gain and brake rotor-induced brake torque oscillations. The adaptive control solution for the variable brake torque gain problem was shown to work experimentally, and the algorithm to eliminate brake torque oscillations was demonstrated in simulation.

In addition, documentation was provided for deferential braking hardware, wheel speed measurement hardware, and a strain-based brake torque sensor that were constructed to test these algorithms. They built some relations between torque needed and the time using both experimental and analytical models. They concluded that the non-adaptive sliding mode brake controller performed well but showed a tracking error when there were parameter mismatches. Although this could be remedied with a higher surface gain, an integral term in the surface, or a switching term, it would likely be at the expense of increased control effort. Both adaptive algorithms reduced velocity tracking error and had their parameters converge to the correct value. The smooth adaptation scheme converged as expected, and the nonsmooth adaptation algorithm converged in a linear matter, chattering at a low frequency once it reached the correct parameter value. For this application, the nonsmooth parameter adaptation law gave better results because it had less of a tendency to over/undershoot the correct parameter value when the initial parameter error was large [3].

Shankar et al. [4] Developed a fault-free model of the pneumatic subsystem of the air brake system. Their model can be used in brake control and diagnostic applications. Current enforcement inspections were done manually and hence were time consuming and subjective. The long- term objective was to develop a modelbased, performance based diagnostic system that will automate enforcement inspections and help in monitoring the condition of the air brake system.

Such a diagnostic system can update the driver on the performance of the brake system during travel and with recent advancements in communication technology. 
This information can be remotely transferred to the brake inspection teams. The model of the pneumatic subsystem correlates the pressure transients in the brake chamber with the brake pedal actuation force and the brake valve plunger displacement. An experimental test bench was set up at Texas A\&M University and the experimental data is used to corroborate the results obtained from the model. Mainly they found a relation between the pressure needed inside the brake system and time. They concluded that the model was able to predict the beginning and the end of each brake application accurately. The steady state values are also accurately predicted by the model in all the cases. It can be observed that the model responded well to various supply pressures. The model also predicted the start and the termination of the exhaust phase accurately.

\section{DERIVING GOVERNING EQUATIONS (MATHEMATICAL MODEL)}

The creation of a pneumohydraulic brake drive with the variable transfer attitude requires realization of a complex of works on modeling transients in it, research of influence of the basic design data of a contour on quality of its work. With this purpose the dynamic circuit of a pneumohydraulic drive with the variable transfer attitude relation-(see figure ((1)) was developed in view of the concentrated parameters (mass of a liquid $\mathrm{m}_{\mathrm{i}}$, pliability $\mathrm{Yi}$, hydraulic resistance $\mathrm{R}_{\mathrm{i}}$ ).

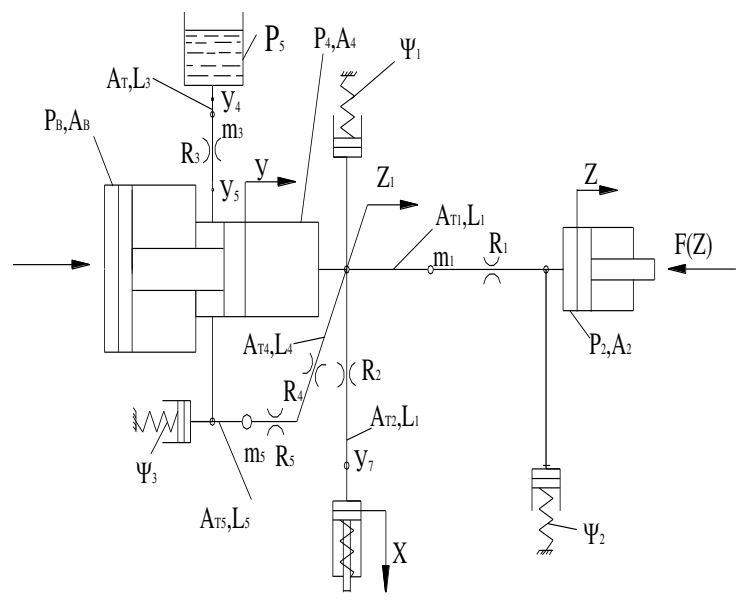

Figure (1) the dynamic circuit pneumohydraulic with the variable transfer attitude (relation)

On the dynamic circuit as shown: $\mathrm{y}_{\mathrm{i}}$ - units of a circuit; $\mathrm{Y}, \mathrm{Z}, \mathrm{X}, \mathrm{Z}_{1}$ coordinate of a rule(situation) accordingly of pistons of the main and executive cylinders, converter of pressure and moving of a liquid in a highway; $\mathrm{p}_{\mathrm{B}}, \mathrm{p}_{1}, \mathrm{p}_{2}, \mathrm{p}_{3}, \mathrm{p}_{4}$, $\mathrm{p}_{5}$, - pressure of air in a pneumatic cavity and pressure of a liquid accordingly in working cavities of the main and executive cylinders, under the piston of the converter of pressure, and pressure inside cavity of the pneumohydraulic cylinder, or tank respectively. $A_{B}, A_{1}, A_{2}, A_{3}, A_{4}$, - area of the piston according to a pneumatic cavity, 
working cavities of the main and executive cylinders, converter of pressure, inside the cavity respectively; $\mathrm{Y}_{1}, \mathrm{Y}_{2}, \mathrm{Y} 3$, - pliability of a circuit given accordingly in units $\mathrm{Y}_{1}$, $\mathrm{y}_{2}, \mathrm{Y}_{3} ; \mathrm{A}_{\mathrm{i}}, \mathrm{L}_{\mathrm{i}}$ - area of through passage sections of pipelines of the appropriate sites and their lengths; $\mathrm{F}(\mathrm{z})$ - characteristic of the brake mechanism force.

For drawing up of the equations of motion, the laws of units and contours are used, and also the nonlinear characteristics of the brake mechanism and converter of pressure are taken into account. Dynamics changes of a considered pneumohydraulic drive are described by the following equations:

In $\mathrm{z}$-direction, the equation of motion can be written as:

$$
\begin{aligned}
& a_{1} \frac{\mathrm{d}^{2} \mathrm{z}_{1}}{\mathrm{dt}^{2}}+\mathrm{a}_{2} \frac{\mathrm{dz_{1 }}}{\mathrm{dt}}+\left(\mathrm{a}_{3}+\mathrm{a}_{4}\right)\left(\frac{\mathrm{dz_{1 }}}{\mathrm{dt}}\right)^{2} \\
& * \operatorname{sgn} \frac{\mathrm{dz}_{1}}{\mathrm{dt}}+\mathrm{p}_{2}=\mathrm{p}_{1} \\
& \frac{\mathrm{dz}}{\mathrm{dt}}=\frac{\mathrm{dz}}{\mathrm{dt}}-\left(\mathrm{a}_{1}+\mathrm{z}\right) * \\
& \Psi_{2} \frac{\mathrm{dp_{2 }}}{\mathrm{dt}}
\end{aligned}
$$

Similar by in y-direction:

$$
\frac{d y}{d t}=\left\{\begin{array}{ccc}
a_{5} \frac{d z_{1}}{d t}+a_{6} \frac{d x}{d t}+\left(a_{7}-y\right) \psi \frac{d p_{1}}{d t} & \text { at } & 0 \leq p_{3} \leq p_{3}^{\prime \prime} \\
a_{5} \frac{d z_{1}}{d t}+a_{8} \frac{d y_{3}}{d t}+\left(a_{7}-y\right) \psi \frac{d p_{1}}{d t} & \text { at } & p_{3}>p_{3}^{\prime \prime}
\end{array}\right.
$$

Also these equations are depending on pressure values such that:

$$
\begin{aligned}
& \text {-If } P_{3}^{\prime} \leq P_{3} \leq P_{3}^{\prime \prime} \\
& a_{10} \frac{d^{2} x}{d^{2}}+a_{11} \frac{d x}{d t}+\left(a_{12}+a_{13}\right)\left(\frac{d x}{d t}\right)^{2} * \\
& \quad \text { ggn } \frac{d x}{d t}+p_{3}=p_{1} \\
& \text {-If } P_{3}>P_{3}^{\prime \prime} ; \\
& a_{14} \frac{d^{2} y_{3}}{d^{2}}+a_{15} \frac{d y_{3}}{d t}+\left(a_{16}+a_{17}+a_{18}\right)\left(\frac{d_{3}}{d t}\right)^{2} * \\
& \quad \operatorname{sgn} \frac{d_{3}}{d t}+p_{4}=p_{1}
\end{aligned}
$$

-If $\mathrm{P}_{4} \leq \mathrm{P}_{5}$

$$
\begin{aligned}
& a_{19} \frac{d^{2} y_{2}}{{d t^{2}}^{2}}+a_{20} \frac{d_{2}}{d t}+\left(a_{21}+a_{22}\right)\left(\frac{d_{2}}{d t}\right)^{2} * \\
& \operatorname{sgn} \frac{d_{2}}{d t}+p_{4}=p_{5}
\end{aligned}
$$

where

sgn: is defined as signum function, which is a mathematical operation and can be defined as: 


$$
\operatorname{sgn}(x)=\left\{\begin{array}{cc}
1 & x>0 \\
0 & x=0 \\
-1 & x<0
\end{array}\right.
$$

For all last equations to be applicable, the following conditions should be worked:

$$
\begin{array}{ll}
\frac{\mathrm{d}^{2} \mathrm{y}_{2}}{\mathrm{dt}^{2}}=\mathbf{O} & \text { at } \mathrm{P}_{3}<\mathrm{P}_{3}^{\prime} \\
\frac{\mathrm{d}^{2} \mathrm{x}}{\mathrm{dt}^{2}}=\frac{\mathrm{dx}}{\mathrm{dt}}=0 & \text { at } \mathrm{P}_{3}>\mathrm{P}_{3}^{\prime \prime} \\
\frac{\mathrm{d}^{2} \mathrm{y}_{3}}{\mathrm{dt}^{2}}=\frac{\mathrm{dy}_{3}}{\mathrm{dt}}=0 & \text { at } \mathrm{P}_{3} \leq \mathrm{P}_{3}^{\prime \prime} \\
\frac{\mathrm{d}^{2} \mathrm{y}_{2}}{\mathrm{dt}^{2}}=\frac{\mathrm{dy_{2 }}}{\mathrm{dt}}=\mathrm{O} & \text { at } \mathrm{P}_{4}>\mathrm{P}_{5}
\end{array}
$$

also $\frac{\mathbf{d p}_{4}}{\mathrm{dt}}$ can be written as:

$$
\frac{d p_{4}}{d t}=\left\{\begin{array}{cl}
0 & \text { at } p_{4} \leq p_{4 \min } ; \\
{\left[\frac{d y_{1}}{d t}-\left(1-\beta \frac{p_{5}}{p_{4}}\right) \frac{d y}{d t}\right] \frac{p_{4}^{2}}{b\left(y+y_{\min }\right) p_{5}}} & \text { at } p_{4 \min } \leq p_{4} \leq p_{5} ; \\
\frac{d y_{1}}{d t}-a_{8} \frac{d y_{3}}{d t}-a_{5} \frac{d z_{1}}{d t}-\left(a_{7}-y\right)(1-\beta) a_{24} \kappa \psi_{1} e^{-k t} & \text { at } p_{4}>p_{5} ; \\
a_{8}\left(a_{7}-y\right) \psi_{1}+\left(a_{23}+y\right) \psi_{4} & \text { is }
\end{array}\right.
$$

Also the following equation can be concluded from figure (1):

$$
\mathrm{y}_{1}=\mathrm{y}_{2}+\mathrm{y}_{3}
$$

By solving equations (1) to (8), pressure values can be given by the following formulas:

$$
\begin{aligned}
& \mathrm{p}_{1}=\mathrm{a}_{24}\left(1-\mathrm{e}^{-\mathrm{kt}}\right)(1-\beta)+\mathrm{a}_{8} \mathrm{p}_{4} ; \\
& \mathrm{p}_{2}= \begin{cases}\mathrm{a}_{25}\left(\mathrm{~F}_{0}+\mathrm{c}_{1} \mathrm{z}\right) & \text { at } \mathrm{z} \leq \mathrm{z}_{0} ; \\
\mathrm{a}_{25}\left[\mathrm{~F}_{0}+\left(\mathrm{c}_{1}-\mathrm{c}_{2}\right) \mathrm{z}_{0}+\mathrm{c}_{2} \mathrm{z}\right] & \text { at } . \mathrm{z}_{0}<\mathrm{z}<\left(\mathrm{z}_{0}+\mathrm{z}_{01}\right) ; \\
\mathrm{a}_{25}\left[\mathrm{~F}_{0}+\left(\mathrm{c}_{1}-\mathrm{c}_{2}\right) \mathrm{z}_{0}+\left(\mathrm{c}_{2}-\mathrm{c}_{3}\right) \mathrm{z}_{01}+\mathrm{c}_{3} \mathrm{z}\right] & \text { at } . \mathrm{z}>\left(\mathrm{z}_{0}+\mathrm{z}_{01}\right) ;\end{cases} \\
& \mathbf{p}_{3}=\mathbf{a}_{26}\left(\mathbf{x}_{0}+\mathbf{x}\right) .
\end{aligned}
$$

In the given equations, constants can be calculated from boundary and initial conditions given in equation (7) as follows:

$$
\begin{aligned}
& \mathrm{a}_{1}=\rho \mathrm{L}_{1} \mathrm{~A}_{2} / \mathrm{A}_{\mathrm{T} 1} ; \\
& \mathrm{a}_{2}=27.5 \rho v L_{1} \mathrm{~A}_{2} / \mathrm{A}_{\mathrm{T} 1}^{2} ; \mathrm{a}_{3}=0.443 \mathrm{~K}_{\varepsilon} \frac{\mathrm{L}_{1}}{\sqrt{\mathrm{A}_{\mathrm{T} 1}}}\left(\frac{\mathrm{A}_{2}}{\mathrm{~A}_{\mathrm{t} 1}}\right)^{2} ;
\end{aligned}
$$




$$
\begin{aligned}
& \mathrm{a}_{4}=0.5 \xi_{1} \rho\left(\mathrm{A}_{2} / \mathrm{A}_{\mathrm{T} 1}\right)^{2} \text {; } \\
& \mathrm{a}_{5}=\mathrm{A}_{2} / \mathrm{A}_{1} \text {; } \\
& \mathrm{a}_{6}=\mathrm{A}_{3} / \mathrm{A}_{1} \text {; } \\
& \mathrm{a}_{7}=y_{\text {max }}+0.51^{\mathrm{A}_{\mathrm{TI}}} / \mathrm{A}_{1} \text {; } \\
& \mathbf{a}_{8}=\mathrm{A}_{4} / \mathrm{A}_{1} \text {; } \\
& \mathrm{a}_{9}=\mathrm{z}_{\max }+0.51 \mathrm{~L}_{1} \mathrm{~A}_{\mathrm{T} 1} / \mathrm{A}_{1} \text {; } \\
& a_{10}=\rho L_{3} A_{3} / A_{\mathrm{T} 2} \text {; } \\
& \mathrm{a}_{11}=27.5 \rho v L_{2} \mathrm{~A}_{3} / \mathrm{A}_{\mathrm{T} 2}^{2} \text {; } \\
& \mathrm{a}_{12}=0.443 \kappa_{\varepsilon} \rho \frac{\mathrm{L}_{2}}{\sqrt{\mathrm{A}_{\mathrm{T} 2}}}\left(\frac{\mathrm{A}_{3}}{\mathrm{~A}_{\mathrm{T} 2}}\right)^{2} \text {; } \\
& \mathrm{a}_{13}=0.5 \xi_{2} \rho\left(\mathrm{A}_{3} / \mathrm{A}_{\mathrm{TS}}\right)^{2} \text {; } \\
& \mathrm{a}_{14}=\rho \mathrm{L}_{5} \mathrm{~A}_{4} / \mathrm{A}_{\mathrm{T}} \text {; } \\
& \mathrm{a}_{15}=27.5 \rho v L_{5} \mathrm{~A}_{4} / \mathrm{A}_{\mathrm{T} 5}^{2} \text {; } \\
& \mathrm{a}_{16}=0.443 \kappa_{\varepsilon} \rho \frac{\mathrm{L}_{5}}{\sqrt{\mathrm{A}_{\mathrm{T} 5}}}\left(\frac{\mathrm{A}_{4}}{\mathrm{~A}_{\mathrm{T5}}}\right)^{2} \text {; } \\
& \mathrm{a}_{17}=0.5 \xi_{5} \rho\left(\mathrm{A}_{4} / \mathrm{A}_{\mathrm{TS}}\right)^{2} \text {; } \\
& \mathrm{a}_{18}=0.5 \xi_{4} \rho\left(\mathrm{A}_{4} / \mathrm{A}_{\mathrm{T} 4}\right)^{2} \text {; } \\
& a_{19}=\rho L_{3} A_{4} / A_{T 5} \text {; } \\
& a_{20}=27.5 \rho v L_{3} \mathrm{~A}_{4} / \mathrm{A}_{\mathrm{T} 3}^{2} \text {; } \\
& \mathrm{a}_{21}=0.443 \kappa_{\varepsilon} \rho \frac{\mathrm{L}_{3}}{\sqrt{\mathrm{A}_{\mathrm{T} 3}}}\left(\frac{\mathrm{A}_{4}}{\mathrm{~A}_{\mathrm{T} 3}}\right)^{2} \text {; } \\
& \mathrm{a}_{22}=0.5 \xi_{3} \rho\left(\mathrm{A}_{4} / \mathrm{A}_{\mathrm{T3}}\right)^{2} \text {; } \\
& \mathrm{a}_{23}=y_{\min }+\mathrm{L}_{5} \mathrm{~A}_{\mathrm{TS}} / \mathrm{A}_{4} \text {; } \\
& \mathrm{a}_{24}=\mathrm{A}_{\text {в }} \mathrm{p}_{\text {вmax }} / \mathrm{A}_{1} \text {; } \\
& \mathbf{a}_{25}=1 / \mathrm{A}_{2} \text {; } \\
& \mathrm{a}_{26}=\mathrm{c}_{4} / \mathrm{A}_{3},
\end{aligned}
$$

where $\rho$ : is the density of the current liquid; $v$ : is the kinematic viscosity factor of a liquid; $\mathrm{k}_{\varepsilon}$ : is an approximation factor; $\xi_{\mathrm{i}}$ - factor of hydraulic resistance; $\mathrm{y}_{1}$ : displacement moved by the piston of the main cylinder without the account of compression of a liquid; $y_{2}, y_{3}:$ are the displacements of the piston of the main cylinder 
caused by change of volume of a liquid according to acting from the tank and for the account of flow from a working cavity in the system; $c_{1}, c_{2}, c_{3}$ : are the given rigidity of the brake mechanism on the appropriate sites of the characteristic; $\mathrm{z}_{0}, \mathrm{z}_{01}:$ are the length of sites of the characteristic of the brake mechanism; $F_{0}$ : is the effort of preliminary deformation of springs; $\mathrm{c}_{4}$ in the spring vigiclity of the prevue converter valve $\mathrm{k}$ : is the parameter of exhibitors; $\mathrm{P}_{3}^{\prime}, \mathrm{P}_{3}^{\prime \prime}$ : are the pressure appropriate to the beginning and the end of operation of the relay of a delay of time of the converter of pressure; $\beta$ : is the relative initial volume of air in a liquid; $\mathrm{p}_{\mathrm{Bmax}}$ : is the maximal pressure of air; $\mathrm{p}_{4 \min }$ : is the pressure appropriate to the beginning of cavitations of a liquid.

\section{RESULTS, DISCUSSION, AND CONCLUSIONS}

Microsoft Excel and Matlab softwares are used here to calculate and find the final results. The objectives here are to calculate $\mathrm{P}_{1}, \mathrm{P}_{2}$, and $\mathrm{P}_{3} . \mathrm{P}_{1}$ with time (t) and $\mathrm{P}_{4}$ relations are represented graphically. In additions the relation between $\mathrm{P} 2$ and $\mathrm{z}$ will be represented graphically. P3 has a relation with $\mathrm{x}$ which will be represented graphically too. Figure (2) shows the relation between the resulted pressure- $\mathrm{P}_{1}$ and the time, it can be noticed that pressure increases with time in a non-linear behavior. Figure (3) relates the resulted pressure- $\mathrm{P}_{1}$ to the input pressure $\mathrm{P}_{4}$. From this figure it can be noticed that the two pressures have an increase (positive) linear relation. Figure (4) shows the relation between the pressure- $\mathrm{P}_{2}$ with the displacement $\mathrm{z}$ in the case of $\mathrm{z} \leq \mathrm{z}_{\mathrm{o}}$, it can be noticed that as this displacement increases the pressure increases. Figures (5) and (6) show Pressure- $\mathrm{P}_{2}$ vs. the displacement- $\mathrm{z}$, for the two cases when $\mathrm{z}_{\mathrm{o}}<\mathrm{z} \leq \mathrm{z}_{01}$, and $\mathrm{z}>\mathrm{z}_{\mathrm{o}}$ respectively. From these figures the pressure increases linearly as the displacement increases. Figure (7) shows that as the displacement in $\mathrm{x}$-direction increases the pressure $-\mathrm{P} 3$ increases, the relation looks like linear.

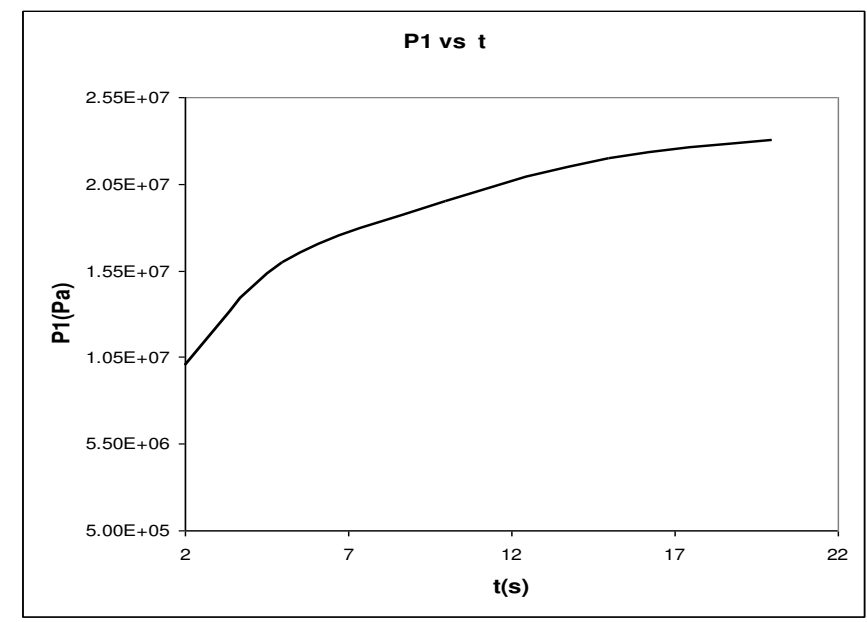

Figure (2) Pressure (P1) vs. time. 


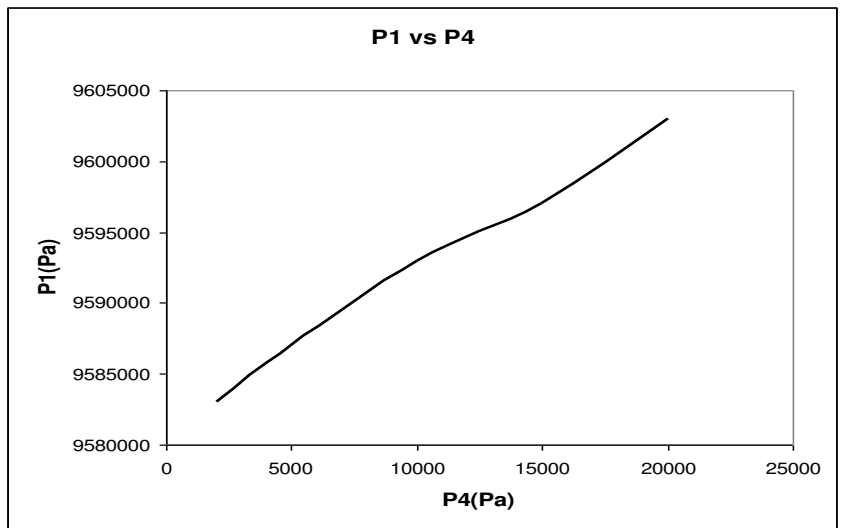

Figure (3) Resulted pressure-P1 vs. input pressure-P4.

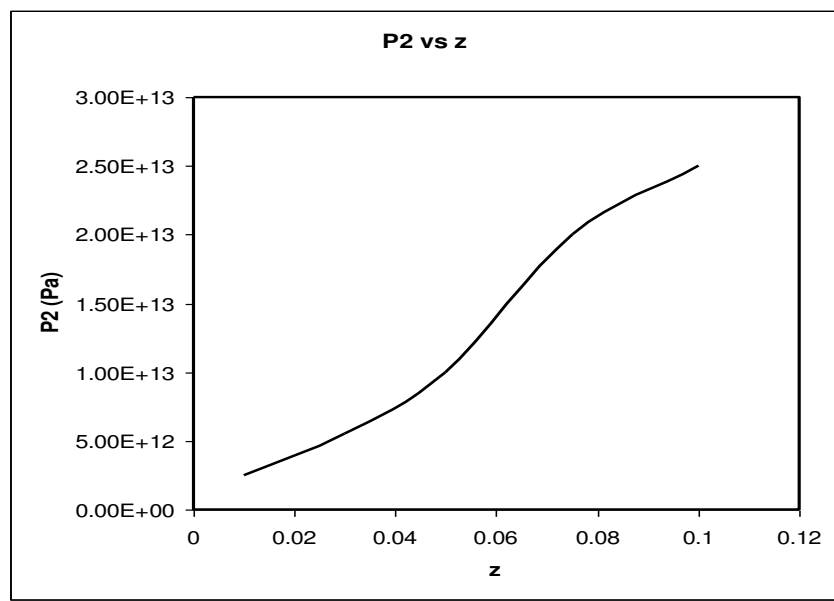

Figure (4) Pressure-P2 vs. the displacement- $\mathrm{z}(\mathrm{m})$, for the case when $\mathrm{z} \leq \mathrm{z}_{0}$.

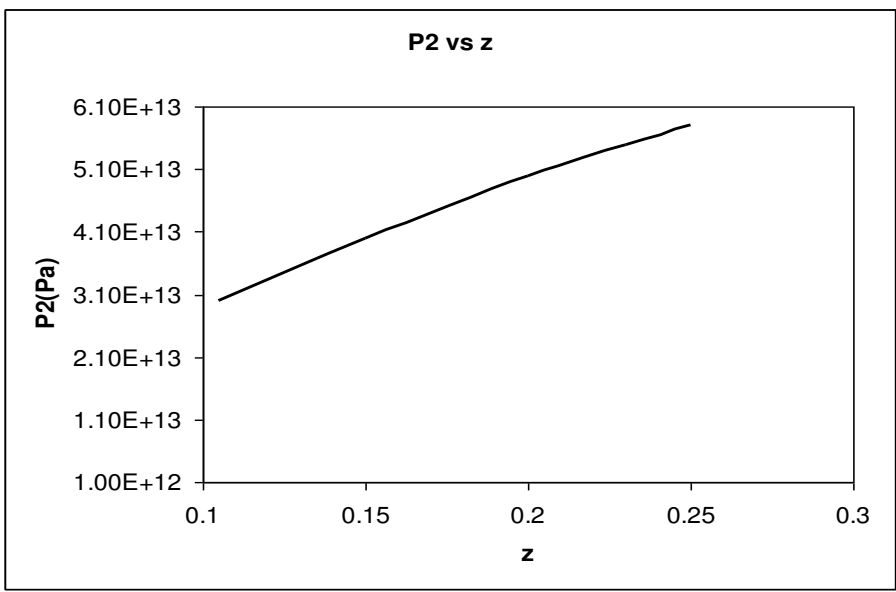

Figure (5) Pressure-P2 vs. the displacement- $\mathrm{z}(\mathrm{m})$, for the case when $\mathrm{zo}<\mathrm{z} \leq \mathrm{z}_{01}$. 


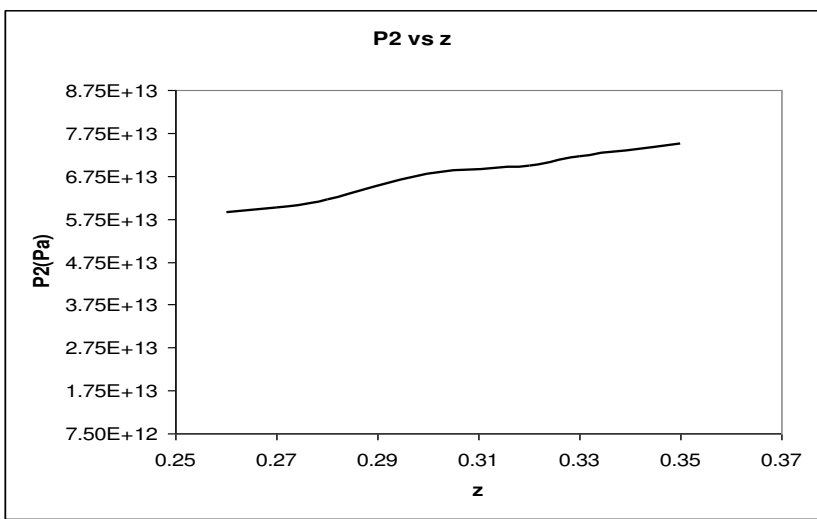

Figure (6) Pressure-P2 vs. the displacement-z (m), for the case when $\mathrm{z}>\mathrm{z}_{01}$.

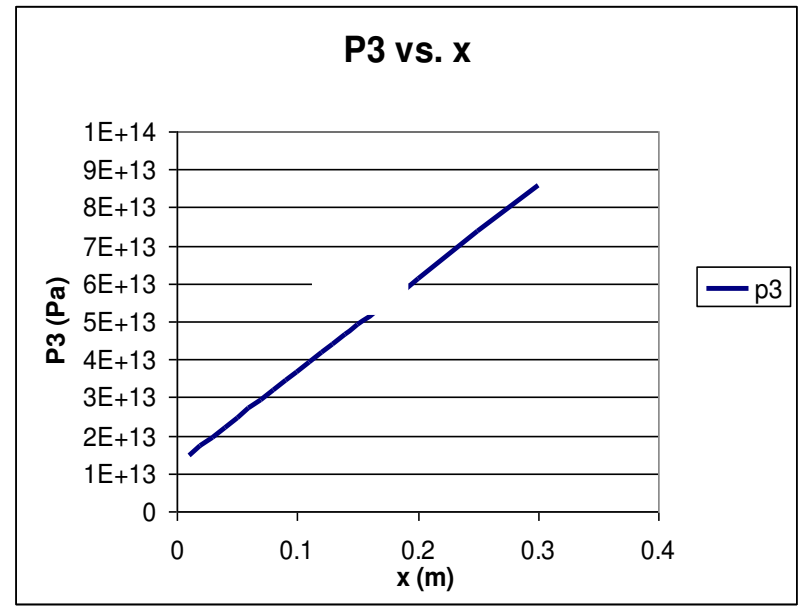

Figure (7) Pressure-P3 vs. the displacement-x.

\section{REFERENCES}

[1] R. Guner, , Yavuz.N., Kopmaz, O., Ozturk, F., and Korkmas, I. 2004. "Validation of analytical model of vehicle brake system", International journal of vehicle design, Vol. 35, No. 4, pp. 331-348.

[2] J.K Hedrick, and Uchanski, M. 2001."Brake System Modeling and Control" California PATH Research Report, University of California, Berkeley, UCB-ITSPRR-2001-25.

[3] N. Maede, 1997." Development of an intelligent cruise controsuperior in several scenarios". Mitsubishi Motors Corporation Report, Japan.

[4] C. Shankar Subramanian, Swaroop Darbha and K. R. Rajagopa,2003," Modeling the Pneumatic Subsystem of a S-cam Air Brake System" Texas Transportation Institute, Texas A\&M University System, College Station, Texas 77843-3135. 
النظام الرياضي لنظام بريك نيوماتي هيدروليكي مع محول ضغط

\section{د. صايل فياض + د. سليمان أبو العين + د. وليد المؤمني}

هذا العمل يقدم نموذجا رياضيا مقترحا لنظام بريك نيوماتي هيدروليكي ، حيث تم تحديد كل العناصر

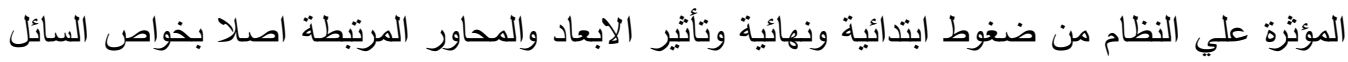

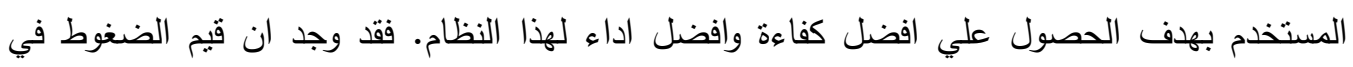
النظام تزيد مع الزمن، كذلك مع المسافة التي يتحركها المكبس. 